\title{
HEART RATE ANALYSIS DIFFERENTIATES DIALEPTIC COMPLEX PARTIAL TEMPORAL LOBE SEIZURES FROM AURAS AND NON-EPILEPTIC SEIZURES
}

\author{
Gisele R. de Oliveira, 1,2 , Francisco de A.A. Gondim ${ }^{1,2}$, \\ R. Edward Hogan ${ }^{1,3}$, Francisco H. Rola ${ }^{2}$
}

\begin{abstract}
The distinction of non-epileptic from epileptic events is difficult even for experienced neurologists. We retrospectively evaluated 59 dialeptic events from 27 patients admitted for video EEG monitoring to check whether heart rate (HR) analysis could help in differentiating dialeptic complex partial temporal lobe seizures (TLS) from dialeptic simple partial TLS, and non-epileptic dialeptic events. Baseline HR was increased in the simple partial TLS in comparison to complex partial TLS and non-epileptic groups $(p<0.05)$. HR increase accompanied each individual dialeptic complex partial TLS $(100 \%$ of the events, $p<0.05)$ bur HR returned to baseline in the post-ictal phase. Ictal HR was not altered in the non-epileptic or simple partial TLS groups. Our findings suggest that ictal centrally mediated tachycardia is characteristic of dialeptic TLS (both tachycardia and bradycardia have been reported during TLS). This finding may be used as a criterion to distinguish dialeptic complex partial TLS from simple partial and non-epileptic dialeptic events.
\end{abstract}

KEY WORDS: heart rate, dialeptic seizures, temporal lobe epilepsy, epileptic auras.

\begin{abstract}
A análise da freqüência cardíaca diferencia crises dialépticas parciais complexas de auras e crises não epilépticas

RESUMO - A distinção entre eventos não epilépticos de epilépticos é difícil mesmo para neurologistas experientes. Analisamos 59 eventos dialéticos de 27 pacientes internados para monitorização por video-EEG para checar se a análise da frequência cardíaca (FC) poderia auxiliar na diferenciação de crises dialépticas parciais complexas de crises dialépticas parciais simples e eventos dialépticos não epilépticos. A freqüência cardíaca basal estava aumentada nos pacientes com crises parciais simples em comparação com o período basal dos grupos parcial complexa e não epiléptico $(p<0,05)$. Houve aumento da freqüência cardíaca em cada crise dialéptica parcial complexa $(100 \%$ dos eventos, $\mathrm{p}<0,05)$, mas a FC retornou aos níveis basais na fase pós-ictal. A FC ictal não foi alterada nos grupos de crises não epiléticas e nos pacientes com crises parciais simples. Nossos achados sugerem que a taquicardia ictal com mediação central é característica de crises parciais complexas dialépticas (tanto taquicardia quanto bradicardia têm sido relatados durante crises temporais parciais complexas). Tal achado poderá ser utilizado como critério para diferenciar crises dialépticas parciais complexas de crises dialépticas parciais simples e eventos dialépticos não epilépticos.
\end{abstract}

PALAVRAS-CHAVE: frequência cardíaca, crises dialépticas, epilepsia do lobo temporal, auras epilépticas.

Autonomic nervous system changes are common in epileptic and non-epileptic seizures and may cause sudden death in epileptic patients ${ }^{1-5}$. These autonomic changes are not fully understood, but may be the result of increased motor activity, emotional distress or modulation of central autonomic circuitry.

Several studies have demonstrated that heart rate (HR) commonly increases during seizures ${ }^{1-7}$, but bradycardia ${ }^{8}$ and even cardiac asystole ${ }^{9}$ can occasionally occur during temporal lobe seizures. Opherk et al. ${ }^{7}$ demonstrated that ictal HR analysis could aid in dif- ferentiating non-convulsive epileptic seizures from non-epileptic events. They proposed that in "quiet spells", if ictal HR was increased by more than $30 \%$ of baseline, there was a $97 \%$ chance that the spell was epileptic. However, no adequate control for movement was performed and HR was evaluated only during the first 10 seconds of the ictal period and postictally only in the first 1-2 minutes.

In this study, we evaluated the HR changes in epileptic and non-epileptic events with minimal amount of motor activity and staring to establish whether

\footnotetext{
${ }^{1}$ Department of Neurology, Saint Louis University, St. Louis, Missouri, USA; ${ }^{2}$ Universidade Federal do Ceará, Fortaleza, Ceará, Brazil ${ }^{3}$ Department of Neurology, Washington University School of Medicine, St. Louis, Missouri, USA.
}

Received 31 October 2006, received in final form 20 March 2007. Accepted 2 May 2007. 
patterns of HR progression could differentiate them. For this purpose, we compared temporal lobe seizures with particular clinical manifestations, i.e. alteration of consciousness, staring, and loss of or minimal motor activity (therefore fulfilling the criteria of dialeptic seizures using the classification of ictal semiology proposed by Lüders ${ }^{6}$ ) with similar non-epileptic and partial temporal lobe seizure (TLS) counterparts. Part of this study has been reported in abstract form elsewhere ${ }^{10}$.

\section{METHOD}

Patients - We performed a retrospective analysis of 59 dialeptic events - defined as seizures characterized by alteration of consciousness, staring, and minimal motor activity $^{6}$ - from 27 patients admitted for video EEG monitoring (11 men, 16 women; maximum of 3 events/patient to avoid selection bias) at the Saint Louis University Epilepsy Unit. This study was approved by the Institutional Review Board from Saint Louis University.

Each dialeptic event - epileptic or non-epileptic - was classified according to the presence of ictal scalp EEG changes in: 1) "Dialeptic complex partial TLS": well-formed, high amplitude, ictal rhythmic theta and delta frequencies ( $N=28$ events); 2) Non-epileptic dialeptic seizures: spells in patients with a final clinical diagnosis of non-epileptic seizures, without background changes on scalp EEG ( $\mathrm{N}=20$ events); 3) Dialeptic aura (simple partial TLS): dialeptic events in patients with known temporal lobe epilepsy, not associated with background changes on scalp EEG ( $\mathrm{N}=11$ events).

Data acquisition - We analyzed the HR, as well as behavioral changes and EEG patterns during, and $1 \mathrm{~h}$ prior to and $1 \mathrm{~h}$ after each event. HR was measured by counting the QRS complex in 10s epochs throughout 3 different periods: baseline [one 10s epoch every $1 \mathrm{~min}$ for $10 \mathrm{~min}$ starting $1 \mathrm{~h}$ prior to each seizure (from -60 to $-50 \mathrm{~min}$ ); every $10 \mathrm{~min}$ from 50 until $10 \mathrm{~min}$ prior to the seizure $(-50,-40$, $-30,-20,-10 \mathrm{~min}$ ) and every $1 \mathrm{~min}$ from $5 \mathrm{~min}$ until the ictal onset $(-5,-4,-3,-2,-1,-0.5 \mathrm{~min}$ ), ictal (one $10 \mathrm{~s}$ epoch every 30s) and post-ictal (one 10s epoch every $30 \mathrm{~s}$ in the first minute, every $1 \mathrm{~min}$ during $10 \mathrm{~min}$ (from +1 to +10 $\mathrm{min})$, and thereafter every $10 \mathrm{~min}$ until $60 \mathrm{~min}$ post event (from +10 to $+60 \mathrm{~min}$ ). The onset of the electrographic TLS events was established by the presence of scalp EEG changes and was considered as the initial the initial point to start ictal HR measurements in the dialeptic complex partial TLS. The onset of a non-epileptic dialeptic event was defined by the observation of a behavioral change and patient's subsequent report or family's assessment (in each event the patient or relative pushed the button to indicate the onset of the event). Patients with non-epileptic events were exhaustively investigated, being admitted for continuous inpatient monitoring during several days in at least one occasion. Most of them had more than one hospital admission for inpatient monitoring. The aura (partial TLS) onset was defined by a behavioral change during monitoring, which was not considered by the patient to be his/her usual sei- zure event. None of these events progressed to full-blown complex TLS with scalp EEG changes.

Statistical analysis - We used ANOVA for repeated measures and Bonferroni's test to evaluate HR changes during the event progression (baseline versus Ictal versus post-ictal periods) for each individual seizure, within each group and between the different groups. Mean values from the first $30 \mathrm{~min}$, last 10, 5 and $1 \mathrm{~min}$ of baseline monitoring and the first 10 and last 30 min of the post ictal period were also compared with the baseline HR values to evaluate the progression of HR changes over time. Differences were considered significant if $p<0.05$.

\section{RESULTS}

Mean age was $34.9 \pm 2$ years. There was no significant age difference ( $p>0.05)$ in the 3 groups: $31.2 \pm 2.9$ (complex partial TLS), 40.7 \pm 2.4 (non-epileptic) and $34.2 \pm 4.8$ (simple partial TLS). In addition, there was no difference in gender distribution, history of smoking or obesity between the 3 groups ( $p>0.05$ ). No patient had history of coronary artery disease or cardiac arrhythmia. All complex partial TLS events had duration of at least 30s, and most of them had duration of at least 1 minute. Most of the simple partial TLS (auras) had similar duration, except for few events lasting less than a minute.

Figure shows that the baseline HR was similar ( $p>0.05)$ in the non-epileptic ( $75 \pm 1.4$ beats/min) and complex partial TLS groups $(73 \pm 2.5$ beats $/ \mathrm{min})$ but was increased in the simple partial TLS group: 86 \pm 2.6 beats/min $(p<0.05)$. However, as can be seen in Table, motor activity was not increased during the baseline period in the simple partial TLS. Therefore, this increase in baseline HR observed in the simple partial TLS group was not due to increased activity.

HR increase occurred in each individual complex partial TLS, and as a group HR was increased to $109 \pm 3.2$ beats/min, $p<0.05$ (Figure), with return to the baseline HR in the post ictal phase: $82 \pm 2.4$ beats/ min ( $p>0.05$ ). Bradycardia or unchanged HR was not observed in any complex partial TLS. Sixty-one $\%$ of the complex partial TLS events started on the right and $39 \%$ on the left, with $100 \%$ contralateral spreading. In the non-epileptic and simple partial TLS groups, the HR did not increase in the ictal and postictal phases ( $p>0.05)$ : in the simple partial TLS $91 \pm 2.6$ beats/min (ictal) and $88 \pm 3$ beats/min (post-ictal) and in the non-epileptic events, $78 \pm 1.9$ beats/min (ictal) and $73 \pm 2.5$ beats/min (post-ictal).

Despite the increased baseline HR in simple partial TLS, the HR in the last 10,5 and $1 \mathrm{~min}$ of the baseline simple partial TLS period was not significantly different from the HR values in the first 10, 5 


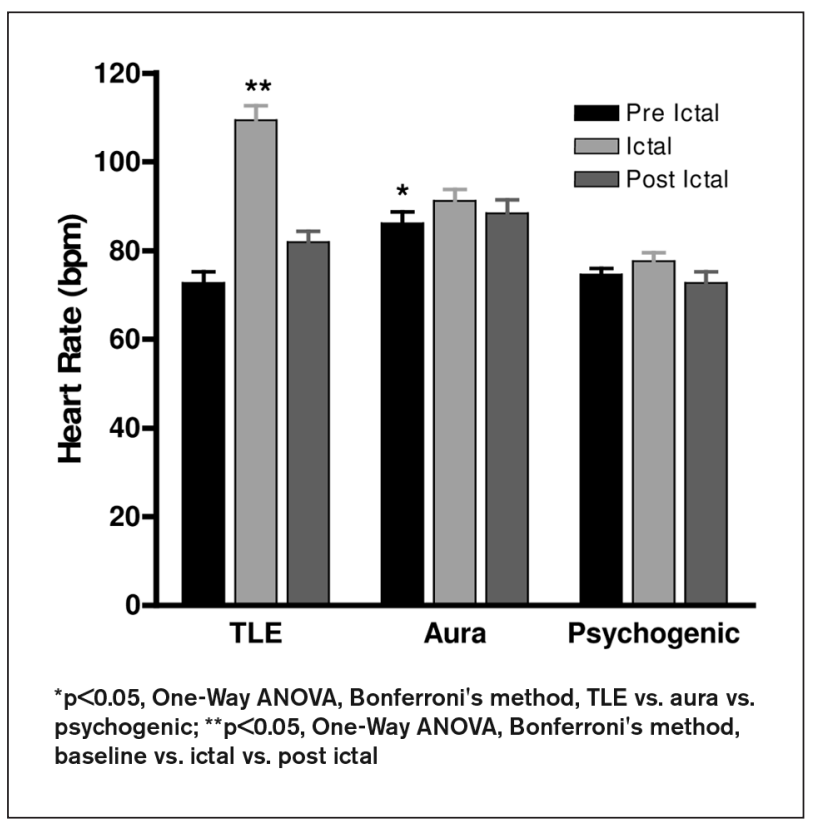

Figure. Heart rate changes in patients with complex partial temporal lobe seizures (TLE), simple partial temporal lobe seizures (aura) and non-epileptic (psychogenic) dialeptic events.

and $1 \mathrm{~min}$ of the baseline: $86 \pm 2.6$ beats/min ( $60 \mathrm{~min}$ mean baseline) versus $90 \pm 3.7,91 \pm 3.8$ and $89 \pm 4$ beats/ $\min$ (last 10, 5 and $1 \mathrm{~min}$ ).

Similarly, the HR in the last 10,5 and 1 min of the baseline simple partial TLS period was not significantly different from the HR values in the first 10, 5 and 1 min of the baseline, in patients with complex partial TLS or non-epileptic seizures: $73 \pm 2.5$ beats $/ \mathrm{min}(60$ min mean baseline) versus $76 \pm 2.8,77 \pm 2.9$ and $78 \pm 3$ beats/min, respectively for the last $10 \mathrm{~min}$, last $5 \mathrm{~min}$ and last $1 \mathrm{~min}$ of the baseline period (complex partial TLS) and $75 \pm 1.4$ beats/min (mean 60 min baseline) versus $75 \pm 1.8,76 \pm 1.8$ and $76 \pm 1.9$ beats $/ \mathrm{min}$, respectively for the last $10 \mathrm{~min}$, last $5 \mathrm{~min}$ and last $1 \mathrm{~min}$ of the baseline period (non-epileptic seizures).

\section{DISCUSSION}

HR changes during seizures are common and may increase the risk of sudden death ${ }^{11}$. Sinus tachycardia is by far the most commonly reported autonomic change during seizures ${ }^{4}$. However, bradycardia and many other types of arrhythmias have been described during focal or generalized epileptic events ${ }^{6,8,9}$. Its mechanisms are not entirely understood, but a recent study has demonstrated altered baroreflex function, decreased total autonomic variability and relative increase in baseline sympathetic tone, which may further explain the propensity to cardiac arrhythmias and sudden death in temporal lobe epilepsy patients ${ }^{11}$. A recent study from India also reported
Table. Motor activity during the baseline period in patients with non-epileptic dialeptic seizures, simple partial dialeptic temporal lobe seizures (TLS) and complex partial dialeptic TLS. Values are expressed as \% of the total patients.

\begin{tabular}{lccc}
\hline & $\begin{array}{c}\text { Non-epileptic } \\
\text { patients (\%) }\end{array}$ & $\begin{array}{c}\text { Simple partial } \\
\text { TLS (\%) }\end{array}$ & $\begin{array}{c}\text { Complex partial } \\
\text { TLS (\%) }\end{array}$ \\
\hline Any sleep & 17.7 & 20 & 29 \\
Standing & 82.3 & 50 & 8.7 \\
Seating & 44.4 & 70 & 50 \\
Walking & 76.9 & 40 & 8.3 \\
\hline
\end{tabular}

autonomic dysfunction in $56.3 \%$ of the epileptic patients $^{12}$. The existence of unilateral parasympathetic cardiomotor representation in the left hemisphere has been reported but recently questioned ${ }^{8}$. Although one study has correlated the amount of dissemination of the epileptiform activity throughout the cortex with the tachycardia magnitude ${ }^{6}$, simple partial seizures can also be associated with HR changes ${ }^{5}$. Experimental data have also proved that selective stimulation of areas that belong to the central autonomic network, such as the insula ${ }^{13}$, can trigger major autonomic changes. Other important factors which can determine autonomic changes include motor activity and emotional distress ${ }^{14}$.

Our study revealed that dialeptic complex partial TLS (which is not associated with significant motor changes) is characteristically accompanied by tachycardia ( $100 \%$ of the events). Since increased motor activity could not be the culprit for the tachycardia, it is likely that it was due to the activation of components of the central autonomic network. Our interpretation is further supported by our observation that tachycardia started with focal EEG changes and was not necessarily related to spreading of the epileptiform activity. Alternatively, one can argue that the tachycardia was emotionally driven, due to selfperception of the seizure. Although we cannot completely rule out this hypothesis, in most of our patients fear was not reported after the event.

Our study also reveals that dialeptic complex partial TLS can be differentiated from dialeptic simple partial TLS (auras) and dialeptic non-epileptic seizures by HR analysis, since no dialeptic non-epileptic seizure or dialeptic partial TLS was associated with tachycardia, whereas $100 \%$ of the complex partial dialeptic TLS caused tachycardia. These findings are also in agreement with Opherk et al. ${ }^{6}$, who demonstrated that ictal HR analysis could aid in differentiating non-convulsive epileptic seizures from non-epileptic events, since in "quiet spells", if ictal HR was 
increased by more than $30 \%$ of baseline, there was a $97 \%$ chance that the spell was epileptic.

A baseline state of enhanced HR was common prior to the dialeptic partial TLS (auras) and was not due to increased motor activity during the baseline period (Table). This finding could be the result of the self-perception (body awareness) of an imminent complex partial TLS, which was not fully developed subsequently, since ictal tachycardia was present in each individual (all) dialeptic complex partial TLS.

In summary, our findings indicate that in TLS associated with a dialeptic state, tachycardia is invariably present. These findings raise the possibility that even without EEG monitoring, one can distinguish complex partial TLS from simple partial TLS and nonepileptic events by looking at conventional HR monitoring.

\section{REFERENCES}

1. Ansakorpi H, J T Korpelainen, H V Huikuri, et al. Heart rate dynamics in refractory and well-controlled temporal lobe epilepsy. J Neurol Neurosurg Psychiatry 2002;72:26-30.
2. Epstein MA, Sperling MR, O Connor MJ. Cardiac rhythm during temporal lobe seizures. Neurology 1992;42:50-53.

3. Freeman R, Schachter SC. Autonomic epilepsy. Sem Neurol 1995;15: 158-166.

4. Leutmezer F, Schernthaner C, Lurger S, et al. Electrographic changes at the onset of epileptic seizures Epilepsia 2003;44:348-354.

5. Nashef L, Walker F, Allen P, et al. Apnea and bradycardia during epileptic seizures: relation to sudden death in epilepsy. J Neurol Neurosurg Psychiatry 1996;60:297-300.

6. Luders H, Noachtar S. Epileptic seizures: pathophysiology and clinical semiology. London: Churchill Livingstone, 2000.

7. Opherk C, Hirsch L. Ictal HR differentiates epileptic from non-epileptic seizures. Neurology 2002;58:636-638.

8. Britton JW, Ghearing GR, Benarroch EE, Cascino GD. The ictal bradycardia syndrome: localization and lateralization. Epilepsia 2006;47: 737-744.

9. Carvalho KS, Salanova V, Markand ON. Cardiac asystole during a temporal lobe seizure. Seizure 2004;13:595-599.

10. Oliveira GR, Gondim FAA, Hogan E. Heart rate analysis can differentiate dialeptic temporal lobe epilepsy from dialeptic auras and dialeptic nonepileptic seizures. Ann Neurol 2003;54(Suppl 7):S55.

11. So EL, Sam MC, Lagerlund TL. Postictal central apnea as a cause of SUDEP: evidence from near- SUDEP incident. Epilepsia 2000;41:14941497.

12. Dutsch M, Hilz MJ, Devinsky O. Impaired baroreflex function in temporal lobe epilepsy. J Neurol 2006;253:1300-1308.

13. Sathyaprabha TN, Satischandra P, Netravathi K, Sinha S, Thennarasu $\mathrm{K}$, Raju TR. Cardiac autonomic dysfunctions in chronic refractory epilepsy. Epilepsy Res 2006;72:49-56.

14. Oppenheimer SM, Gelb A, Girvin JP, et al. Cardiovascular events of human insular cortex stimulation. Neurology 1992;42:1727-1732. 